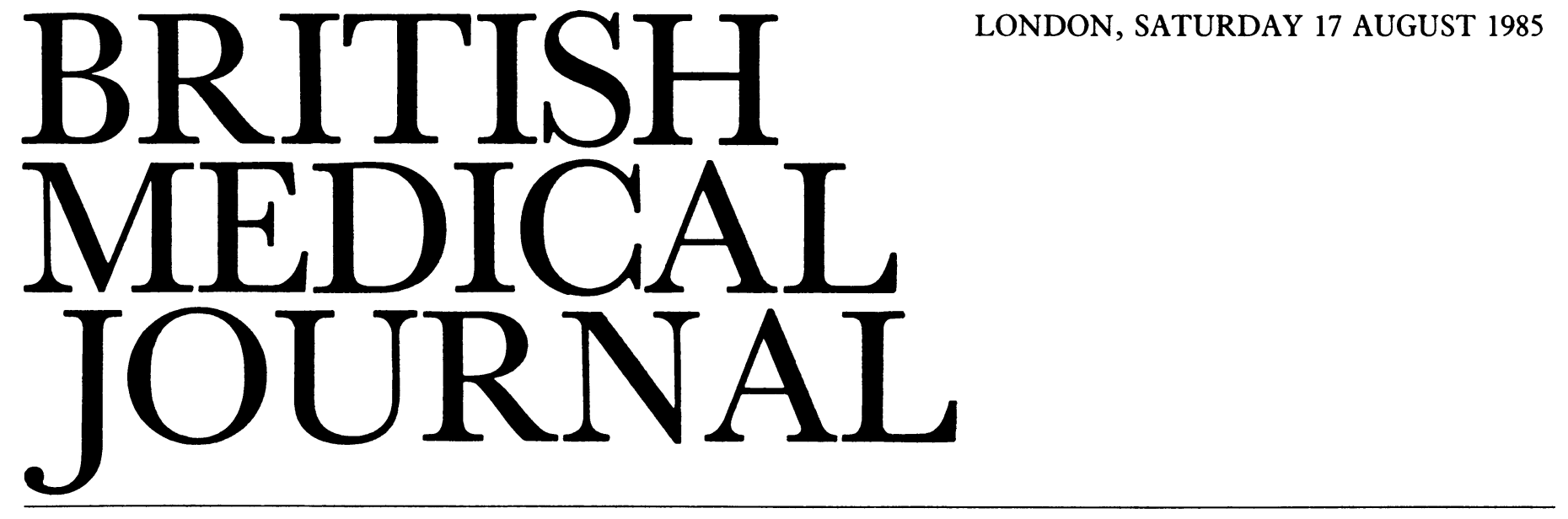

\title{
Malignant hypercalcaemia
}

Malignant disease is one of the commonest causes of hypercalcaemia, carcinomas of the bronchus and breast and reticuloendothelial disorders being most often responsible. ${ }^{\prime}$ Usually skeletal deposits are present and tumour cells are often capable of resorbing bone. Yet the presence or extent of skeletal metastases may not correlate with the presence or degree of hypercalcaemia, for humoral factors secreted by the malignant cells probably cause or augment the hypercalcaemia. ${ }^{2}$ As our knowledge of these factors increases so we shall improve our understanding of the pathogenesis of this form of hypercalcaemia and make a more rational approach to its management.

There are three mechanisms by which the serum concentration of calcium may be raised: firstly, by mobilisation of calcium from bone; secondly, by a reduction in the loss of calcium by the kidneys; and, thirdly, by increased intestinal absorption of calcium. Many malignant tumours secrete factors which may resorb bone by enhancing osteoclastic activity-for example, osteoclast activating factor, a lymphokine secreted by myeloma cells and capable of local bone resorption. ${ }^{3}$ Other factors that may resorb bone in reticuloendothelial disorders include prostaglandins ${ }^{4}$ and interleukin $1 .^{5}$ Prostaglandins are produced by some solid tumours such as breast carcinomas. ${ }^{6}$ More recently, several growth factors derived from tumours (some similar to epidermal growth factor) have been identified and shown to be capable of bone resorption. ${ }^{78}$ Possibly tumours that produce such factors are able to metastasise particularly to the skeleton.

In normal circumstances an increase in mobilisation of bone calcium-unless extremely rapid and widespreadshould not cause much hypercalcaemia because of the hormonal homoeostatic mechanisms and the renal clearance of calcium. Probably, therefore, some tumours produce not only factors responsible for bone resorption but also humoral factors which prevent renal clearance of excess calcium. Such factors are immunologically unlike parathyroid hormone but biologically have a parathyroid hormone like action on the kidney. ${ }^{9}$ They might be responsible for the increased renal tubular reabsorption of calcium that has been shown in malignant hypercalcaemia and is probably an integral part of its pathogenesis. ${ }^{10}$ True ectopic secretion of parathyroid hormone by tumours is extremely rare.

An increased intestinal absorption of calcium may enhance hypercalcaemia, but this is not usually found in malignant disease. Nor has ectopic production of 1,25-dihydroxyvitamin $\mathrm{D}$ been reported, but humoral factors capable of mimicking parathyroid hormone might theoretically enhance renal $1 \alpha$-hydroxylase activity. In practice this does not seem to occur at all often.

How does this knowledge help form a rational approach to the management of malignant hypercalcaemia? When it presents acutely the patient is often considerably dehydrated, and replacement of extracellular fluid should be the first line of treatment. This ensures adequate rehydration and increases glomerular filtration and hence the filtered load of calcium, so helping to counteract any parathyroid hormone like effects on the kidney." A second line of treatment is to attempt to reduce the mobilisation of calcium from bone with agents which specifically inhibit osteoclastic activity. Calcitonin may be given as an intravenous infusion or (preferably) by subcutaneous injection to avoid the side effects of nausea. It is safe and often rapidly effective. ${ }^{12}{ }^{13}$ If the calcitonin is given as an intravenous infusion protein must be added to the solution to prevent its adsorbence to delivery systems.

The hypocalcaemic effect of calcitonin may wear off after about 48 to 72 hours, perhaps owing to down regulation of receptors but it may be prolonged by the simultaneous administration of glucocorticoids. ${ }^{14}$ Glucocorticoids may act in several ways. They may inhibit the resorption of bone induced by osteoclast activating factor, ${ }^{15}$ they may cause lysis of tumour cells, and they may, perhaps, prevent the down regulation of calcitonin receptors thereby prolonging the action of the latter hormone. ${ }^{14}$ In the longer term they may reduce intestinal absorption of calcium by antagonising the intestinal actions of 1,25-dihydroxyvitamin D, though that action does not seem important here. In acute hypercalcaemia, however, glucocorticoids by themselves are often ineffective. ${ }^{16}$ Even in the longer term they may be of use in only about a third of patients or less. ${ }^{1317}$ In general corticosteroids are overused and, apart from their combination with calcitonin for short term treatment, they are probably best employed in the reticuloendothelial disorders.

Diphosphonates are stable analogues of pyrophosphate which may lower blood concentrations of calcium, probably by a direct effect on osteoclastic resorption of bone. They may be given by mouth, but they are absorbed poorly from the intestines and intravenous administration may be preferable in a sick patient. The only diphosphonate 
generally available is etidronate, which is effective in malignant hypercalcaemia, though it is not useful in acute siates because of a delay in the onset of its effect. ${ }^{18}$ The disadvantage of etidronate is that it may cause impairment of bone mineralisation, which limits its dosage and duration of usage. ${ }^{19}$

In the short term all these drawbacks may not be important. The cytotoxic antibiotic mithramycin has a calcium lowering effect, but again this is not immediate. ${ }^{20}$ Its hepatic, renal, and platelet toxicity largely precludes its use, particularly when the patient may later need other cytotoxic regimens. As a last resort additional measures such as haemodialysis or even a single infusion of phosphate may be considered. In the longer term specific antitumour treatment should be given, and measures for lowering calcium concentrations should be continued until they are satisfactory. Antiresorptive treatment should be continued with either subcutaneous calcitonin, with or without glucocorticoids as necessary, or etidronate.

Future hopes for the management of malignant hypercalcaemia lie in two directions. Firstly, new diphosphonate compounds are under development which have effective calcium lowering properties while not interfering with bone mineralisation. ${ }^{2122}$ These are likely to prove of great value in long term management. Secondly, the development of specific parathyroid hormone antagonists ${ }^{23}$ may well provide a new dimension by counteracting any renal component of the disease.

JOHN C STEVENSON

Lecturer and Honorary Senior Registrar,

Endocrine Unit,

Royal Postgraduate Medical School,

London W12 0HS

1 Fisken RA, Heath DA, Bold AM. Hypercalcaemia-a hospital survey. Of Med 1980;49:405-18. 2 Ralston S, Fogelman I, Gardner MD, Boyle IT. Hypercalcaemia and metastatic bone disease: is there a causal link? Lancet 1982;ii:903-5.

3 Mundy GR, Raisz LG, Cooper RA, et al. Evidence for the secretion of an osteoclast stimulating factor in myeloma. N Engl f Med 1974;291:1041-6.

4 Tashiian AH, Voelkel EF, Levine L, et al. Evidence that the bone resorption-stimulating factor produced by mouse fibrosarcoma cells is prostaglandin $\mathrm{E}_{2}$ : a new model for the hypercalcaemia of cancer. Fournal of Experimental Medicine 1972;136:1329-37.

5 Gowen M, Wood DD, Ihrie EJ, McGuire MKB, Russell RGG. An interleukin 1 like factor stimulates bone resorption in vitro. Nature 1983;306:378-80.

6 Bennett A, Charlier EM, McDonald AM, et al. Prostaglandins and breast cancer. Lance 1977;ii:624-6.

7 Todaro GJ, Fryling C, DeLarco JE. Transforming growth factors (TGFs) produced by certain human tumor cells: polypeptides that interact with epidermal growth factor (EGF) receptors. Proc Natl Acad Sci USA 1980;77:5058-62.

8 Ibbotson KJ, D'Souza SM, Ng KW, et al. Tumor-derived growth factor increases bone resorption in a tumor associated with humoral hypercalcemia of malignancy. Science 1983;221:1292-4.

Goltzman D, Stewart AF, Broadus AE. Malignancy-associated hypercalcemia: evaluation with cytochemical bioassay for parat

10 Ralston SH, Fogelman I, Gardner MD, Dryburgh FJ, Cowan RA, Boyle IT. Hypercalcaemia of malignancy: evidence for a non-parathyroid humoral agent with an effect on renal tubular
handling of calcium. Clin Sci 1984;66:187-91.

11 Hosking DJ, Cowley A, Bucknall CA. Rehydration in the treatment of severe hypercalcaemia. Q7 Med 1981;50:473-81.

12 Silva OL, Becker KL. Salmon calcitonin in the treatment of hypercalcemia. Arch Intern Med 1973;132:337-9.

13 Mundy GR, Martin TJ. The hypercalcemia of malignancy: pathogenesis and management. Metabolism 1982;31:1247-77.

14 Binstock ML, Mundy GR. Effect of calcitonin and glucocorticoids in combination in malignan hypercalcemia. Ann Intern Med 1980;93:269-72.

15 Mundy GR, Rick ME, Turcotte R, et al. Pathogenesis of hypercalcemia in lymphosarcoma cell leukemia. Role of an osteoclast activating factor-like substance and mechanism of action for glucocorticoid therapy. Am f Med 1978;65:600-6.

16 Percival RC, Yates AJ, Gray RE, Neal FE, Forrest AR, Kanis JA. Role of glucocorticoids in management of malignant hypercalcaemia. Br Med f 1984;289:287.

17 Thalassinos NC, Joplin G. Failure of corticosteroid therapy to direct the hypercalcaemia of malignant disease. Lancet 1970;ii:537-8.

18 Jung A. Comparison of two parenteral diphosphonates in hypercalcemia of malignancy. Am f Med 1982;72:221-6.

19 Boyce BF, Smith L, Fogelman I, Johnston E, Ralston S, Boyle IT. Focal osteomalacia due to lowdose diphosphonate therapy in Paget's disease. Lancet 1984; ; :821-4.

20 Parsons $V$, Baum $M$, Self $M$. Effect of mithramycin on calcium and hydroxyproline metabolism in patients with malignant disease. Br Med 1 1967; i:474-7.

21 Van Breukelen FJM, Bijvoet OLM, van Oosterom AT. Inhibition of osteolytic bone lesions by (3-amino-1-hydroxypropylidene)-1,1-bisphosphonate (APD). Lancet 1979;i:803-5.

22 Chapuy MC, Meunier PJ, Alexandre CM, Vignon EP. Effects of disodium dichloromethylene diphosphonate on hypercalcemia produced by bone metastases. $\mathcal{F}$ Clin Invest 1980;65:1243-7.

23 Horiuchi N, Holick MF, Potts JT, Rosenblatt M. A parathyroid hormone inhibitor in vivo: design and biological evaluation of a hormone analog. Science 1983;220:1053-5.

\section{The case for compulsory pasteurisation}

In August 1983 compulsory pasteurisation of milk was introduced in Scotland, leading to a fall in milk borne infections. Meanwhile, in England and Wales there was no change in legislation and, as Sharp and his colleagues show ( $p$ 463 ), no fall in the number of infections. This amounts to a convincing case for compulsory pasteurisation throughout Britain.

Milk borne salmonellosis was particularly serious in Scotland during the 1970 s and early 1980s, when 50 outbreaks affected at least 3518 people and caused 12 deaths. In addition, there were several major outbreaks of campylobacter infection. The costs of one salmonella outbreak were estimated to lie between $£ 236000$ and $£ 3222000$ and the mid-range average cost for each patient was $£ 2637 .{ }^{1}$ But after compulsory pasteurisation, during 1983-4, eight outbreaks of milk borne salmonellosis affected only 46 people-all in dairy farming communities. No outbreaks were reported from the general community, whereas 14 general outbreaks had affected over 1090 people in the previous three years.

In 1983 two household episodes of campylobacter enteritis were attributed to raw milk. One of these happened before compulsory pasteurisation, and the other was in a family who had returned from a holiday in England. In 1984 there were no outbreaks of campylobacter enteritis.

Only temporary exemptions from pasteurisation are granted to a few small dairy farms on outer islands, which produce less than $0.02 \%$ of Scottish milk. Concern remains only over dairy farm staff and their families being given free raw milk.

In contrast to Scotland, in England and Wales during 1983-4 some 20 outbreaks of milk borne salmonellosis affected at least 518 people. Twelve of these outbreaks occurred in the general community in people who had bought raw milk direct from dairy farms. In the same years there were six proved outbreaks of campylobacter enteritis and 10 other suspected outbreaks without sufficient microbiological and epidemiological evidence to prove the diagnosis.

Although less than $3 \%$ of the 6000 million litres of milk sold annually in England and Wales is untreated, half of this is produced in the north west, where $70 \%$ of the $1983-4$ outbreaks occurred. Legislation is expected in November 1985 that will reduce the availability of untreated milk from shops_-but it will not forbid direct "farm gate" sales or local retail deliveries of farm bottled raw milk. At present legislation covers only cows' milk, but the milk of goats and sheep should be included as soon as possible. To reduce still further the risks of milk borne infection, farm water supplies need to be better controlled and pasteurisation plants must be well maintained, thoroughly cleaned, and efficiently operated. Failures are sometimes due to insufficient pasteurisation or to contamination of pasteurised milk by raw milk or dirty containers. But these are minor matters compared with the need for compulsory pasteurisation throughout Britain of all animal milk intended for human consumption.

Passionate opponents of compulsory pasteurisation are likely to remain unconvinced for ever since they rely on feelings rather than evidence. Often these arguments seem to rest on a desire not to go against what nature intended. It might be argued that nature never intended man to drink 